\title{
O LÉXICO COMO ELEMENTO DE TEXTUALIZAÇÃO: DA CONCEPÇÃO TEÓRICA À PRÁTICA DIDÁTICA
}

Alessandra Magda de Miranda (UFPB) Mônica Mano Trindade Ferraz (UFPB)

Resumo: Este artigo tem como objetivo demonstrar as relações lexicais, definindo a sinonímia e hiperonímia, como fenômenos de coesão textual e da necessidade de sistematizar esse estudo na prática escolar para que o aluno possa refletir sobre a relevância do léxico dentro da constituição do sentido do texto.

Palavras-chave: Ensino, texto, léxico, sinonímia, hiperonímia.

Abstract: This article aims to demonstrate the lexical relations, defining synonymy and hyperonymy, as phenomena of textual cohesion and the necessity of systematizing such study in school practice so that the student may reflect on the relevance of the lexicon within the constitution of the meaning of the text.

Key words: Teaching, text, lexicon, synonymy, hyperonymy.

\section{CONSIDERAÇÕES INICIAIS}

O ensino de Língua Portuguesa deve ter como foco as práticas de leitura e produção de textos, o que implica desenvolver nos educandos habilidades inerentes ao ato de ler e escrever, entre elas a compreensão de como os textos são construídos/estruturados.

Nesse sentido, buscaremos, neste artigo, apresentar algumas considerações a respeito do trabalho com certas unidades composicionais do texto, destacando o papel desempenhado pelo léxico no processo de textualização. 
Trata-se de um recorte de uma pesquisa de mestrado, já concluída, que se propunha a refletir acerca da importância/ relevância do conhecimento das relações semântico-lexicais para a elaboração textual, evidenciando a necessidade de o professor de Língua Portuguesa contemplar, em suas aulas, atividades de estudo do léxico na perspectiva da textualidade. Tal estudo foi desenvolvido buscando verificar de que modo a ausência de conhecimento do léxico e das relações semântico-lexicais afeta nas produções de textos realizadas por alunos de ensino médio e como uma intervenção pedagógica na qual o estudo das relações lexicais seja desenvolvido pode contribuir nas produções dos alunos participantes dessa vivência.

Neste trabalho, delimitamos a sinonímia e a hiperonímia como relações lexicais relevantes para a constituição do texto e buscamos ressaltar a pertinência do estudo do léxico, sob a perspectiva textual, nas aulas de Língua Portuguesa.

\section{COESÃO E LÉXICO}

Halliday \& Hasan (1976 Apud PALADINO et al., 2006, p. 1) definem a coesão como "o conjunto dos meios linguísticos que asseguram as ligações intra e interfrásticas, que permitem a um enunciado oral ou escrito aparecer como um texto". Eles ainda asseguram que a coesão acontece "quando a 
interpretação de algum elemento no discurso é dependente da de outro". Isso nos permite afirmar que tal propriedade compreende a dependência de sentido entre elementos de um discurso, de modo que a decodificação/entendimento de um depende da compreensão/identificação do outro.

Corroborando com essa ideia, Koch (2008, p. 45) conceitua essa condição de textualidade como sendo "o fenômeno que diz respeito ao modo como os elementos linguísticos presentes na superfície textual se encontram interligados entre si, por meio de recursos também linguísticos, formando sequências veiculadoras de sentidos". Temos, portanto, que a coesão refere-se ao encadeamento semântico entre termos que nos permite retomar, reiterar ou remeter para algo designado por alguma expressão e contribui para a composição e compreensão do sentido do todo, isto é, para a constituição da continuidade do texto.

Nas palavras de Antunes (2005, p. 47), a coesão é "a propriedade pela qual se cria e se sinaliza toda espécie de ligação, de laço, que dá ao texto unidade de sentido ou unidade temática". Assim, sua função é "criar, estabelecer e sinalizar os laços que deixam os vários segmentos do texto ligados, articulados, encadeados". Em outras palavras, 
trata-se de um mecanismo realizado, basicamente, por meio de relações semânticas que vão sendo instituídas ao longo do texto.

Essas relações que atribuem continuidade às nossas ações verbais são estabelecidas por meio de elos, aos quais chamamos nexos textuais. De acordo com a proposta de Halliday e Hasan (1989 Apud ANTUNES, 2010, p. 118), os nexos estabelecidos podem criar relações de equivalência, contiguidade, associação e conexão/sequenciação entre dois ou mais pontos do texto.

Os nexos de equivalência são estabelecidos "sempre que dois segmentos de um mesmo texto assumem a condição de atualizarem a mesma referência e/ou o mesmo sentido, ou ainda, apenas, o mesmo sentido" (ANTUNES, 1996, p. 66). Os de contiguidade acontecem quando duas ou mais expressões, apesar de não estarem relacionadas ao mesmo referente, carregam relações semânticas que contribuem para a continuidade do texto. Os de associação, por sua vez, são estabelecidos sempre que existe uma relação de proximidade semântica entre duas ou mais unidades linguísticas. O estabelecimento da coesão por meio desse tipo de nexo ocorre porque, devido à proximidade de sentido, algumas expressões tendem a "aparecer em contextos 
similares ("em colocação") com outras semanticamente relacionadas" (ANTUNES, 1996, p. 75). E os nexos de conexão são as relações semânticas estabelecidas entre segmentos do texto através do uso de conectivos (conjunções, preposições, advérbios e locuções adverbiais).

Em linhas gerais, podemos dizer que a coesão textual se realiza por meio de três relações textuais, todas de natureza semântica, diferenciando-se apenas em relação aos tipos de nexos estabelecidos. São elas: reiteração (nexos de equivalência e contiguidade), associação (nexos de associação) e conexão (nexos de conexão ou sequenciação).

As relações de reiteração dão-se pelos mecanismos de repetição e substituição lexical; as de associação ocorrem por meio dos procedimentos de seleção lexical, ou seja, dizem respeito às relações entre as palavras de mesmo campo semântico; as de conexão referem-se às relações semânticas estabelecidas pelo uso de conectores.

Dessa forma, observaremos, neste artigo, os elos coesivos que proporcionam os nexos de reiteração e que ocorrem por meio do mecanismo da substituição, por serem realizados a partir das relações semânticas entre unidades lexicais, uma vez que nosso intuito maior é proporcionar uma reflexão a respeito da importância do conhecimento das relações 
semântico-lexicais para o processo de elaboração textual, conforme apresentado inicialmente.

\section{A SUBSTITUIÇÃO LEXICAL}

A substituição lexical consiste num recurso que, além de contribuir para a continuidade/progressão textual, é capaz de evidenciar a inter-relação semântica entre as partes do texto, tendo em vista as relações de sentido entre o termo de referência (termo substituído) e seus substituidores. Nesse sentido, de acordo com Antunes (2005, p. 97), "substituir uma palavra por outra supõe um ato de interpretação, de análise, com o objetivo de avaliar a adequação do termo substituidor quanto ao que se pretende conseguir". Além disso, convém ressaltar que esse procedimento colabora também para o teor de informatividade do texto, pois o uso de expressões diferentes para remeter a um mesmo referente permite que novas informações a respeito dele sejam acrescentadas.

No que diz respeito às relações estabelecidas por meio da substituição lexical, ressaltamos que esse é um procedimento que pode ser realizado por meio de alguns recursos e delimitamos, entre eles, a sinonímia e a hiperonímia. 


\subsection{A SINONÍMIA}

Não é possível pensar na existência de sinônimos perfeitos, pois não conseguimos encontrar, em nosso idioma, duas palavras que se substituem em todo e qualquer contexto, mantendo o mesmo sentido. Como afirma o próprio Lyons (1979, p. 435), “é muitas vezes impossível dar o significado de uma palavra sem inseri-la num contexto". A esse respeito, Ilari e Geraldi (2006, p. 46, grifos dos autores) afirmam que "a significação de uma palavra é o conjunto de contextos linguísticos em que pode ocorrer, então é impossível encontrar dois sinônimos perfeitos".

Ilari e Geraldi (2006) destacam ainda que se trata de uma relação semântico-lexical que representa as escolhas feitas pelos locutores, visto que as expressões sinônimas passam por um tipo de especialização de sentido. Desse modo, esclarecem que:

as expressões sinônimas são, ainda assim, expressões entre as quais os locutores escolhem: a escolha é, no caso, uma "procura da palavra exata" (como na pena do escritor que corrige um texto já escrito), a mostrar que duas expressões não são igualmente adequadas aos fins visados; essa escolha traduz frequentemente a preocupação de evocar ou respeitar um determinado nível de fala, um determinado tipo de interação, ou mesmo um certo jargão profissional" (ILARI e GERALDI, 2006. p.47). 
Logo, é possível afirmar que a sinonímia, além de ser um fenômeno contextual, está atrelada às intenções dos falantes, isto é, no instante da produção de um enunciado, o autor escolhe, dentre várias possibilidades de substituição, aquela que mais se adapta às suas pretensões/aos seus objetivos para aquele momento. Isso reforça a tese de que a determinação dos sinônimos não pode ser feita, como se trabalhou na escola por um bom tempo, através do uso de listas de palavras dissociadas de um contexto, pois tal relação de sentido envolve tanto a situação de uso da língua como as pretensões do falante/autor.

Além disso, essa relação de equivalência de sentido tem como função primordial o encadeamento das informações de um texto, o que promove a constituição da unidade de sentido de uma ação de linguagem. Assim, podemos afirmar que a substituição lexical por meio dos sinônimos contribui para que se mantenha a continuidade temática, seja de um parágrafo específico, seja do texto como um todo, pois possibilita a formação dos nexos que marcam a sequência do texto. De acordo com Antunes (2005, p.100), essa substituição repercute "no caráter informativo e na força persuasiva do texto, pois pode elevar o grau de interesse do interlocutor pela forma como as coisas são ditas". 
A passagem abaixo exemplifica como a sinonímia pode atuar no estabelecimento da coesão textual:

Texto 01

O corpo do menino de 11 anos morto na quarta-feira (5) após ter sido atropelado na saída da escola em Sertãozinho (SP) vai ser enterrado na tarde desta quinta-feira (6). O garoto foi atingido por um carro ao deixar a instituição de ensino no bairro Cohab VIII. [...] A motorista do carro que atropelou o adolescente prestou depoimento na delegacia e foi liberada.

Fonte:(G1 Ribeirão e Franca ${ }^{1}$, 06 de junho de 2013).

Nesse exemplo, palavras semanticamente equivalentes (sinônimas) foram usadas para reiterar informações apresentadas anteriormente. Os termos garoto e adolescente fazem referência a / substituem menino, formando um conjunto de sinônimos; já instituição de ensino substitui escola formando um segundo par.

Observando com acuidade essas substituições, percebermos que elas contribuem para o estabelecimento da continuidade temática, pois formam um elo entre as informações apresentadas, possibilitando a constituição da unidade de sentido do texto. Nas palavras de Antunes

1 Disponível em: http://g1.globo.com/sp/ribeirao-preto-franca/noticia/2013/06/menino-de11-anos-morre-atropelado-na-saida-da-escola-em-sertaozinho.html 
(2005, p.102, grifos da autora), são "nós que ligam subpartes do texto. Elas tecem o texto; elas são elementos de sua organização e construção".

\subsection{A HIPERONÍMIA}

Outra relação semântico-lexical que pode ser utilizada como recurso para o procedimento da substituição lexical é a hiperonímia. De acordo com Antunes (2005, p.102), consideram-se hiperônimos "palavras gerais, palavras superordenadas ou nomes mais genéricos, com os quais se nomeia uma classe de seres ou abarcam todos os membros de um grupo". Para compreendermos tal definição, é preciso considerar que algumas palavras podem apresentar um sentido mais restrito e outras, um sentido mais geral.

Assim, a relação estabelecida entre uma palavra de sentido mais geral e outra de sentido mais específico constitui a hiperonímia, enquanto a relação entre um termo de sentido mais específico e outro mais genérico constitui a hiponímia. Segundo Lyons (1979, p.483), esses tipos de relações de sentido entre termos possibilitam-nos sermos mais "genéricos ou mais específicos de acordo com as circunstâncias".

Para compreendermos melhor essa questão, passemos a uma breve análise do texto abaixo, produção na qual o uso dos hiperônimos funciona como recurso coesivo. 
Texto 02

Estrela da Volkswagen no Salão do Automóvel de São Paulo de 2012, o Fusca começou a chegar às lojas em novembro do ano passado. À época, a reportagem da Autoesporte constatou que o novo besouro estava sendo vendido com ágio de até $R \$ 11 \mathrm{mil}$ sobre o preço de tabela. A prática, infelizmente, é comum entre os carros recém-lançados no mercado, que depois de algum tempo costumam voltar ao valor sugerido pela montadora. [...] Autoesporte consultou concessionárias no Rio de Janeiro e em São Paulo. A maior alta foi encontrada na capital paulista. O vendedor nos ofereceu um Fusca, com câmbio automático, “completão", por R\$ 119 mil. Nesta versão, o carro parte de $\mathrm{R} \$$ 84.510. Assustados com o preço, perguntamos se este valor incluía todos os opcionais. A resposta do funcionário foi positiva. De acordo com a seção "monte seu carro" no site da VW (ferramenta que permite visualizar as configurações do veículo), caso adicionássemos todos os opcionais possíveis, que incluem, entre outros itens, faróis de xenon, bancos esportivos e teto panorâmico, o valor máximo do modelo seria de $\mathrm{R} \$$ 106.717, cifra $\mathrm{R} \$ 12.283$ menor que o cobrado pelo vendedor.

Fonte: (Autoesporte'2, 25 de junho de 2013).

2 Disponível em: http://revistaautoesporte.globo.com/Noticias/noticia/2013/06/nas-lojasdesde-novembro-volkswagen-fusca-e-vendido-com-sobrepreco.html 
Nesse exemplo, podemos perceber que incialmente houve a repetição do hipônimo fusca, que, em seguida, foi retomado pelos hiperônimos carro, veículo e modelo, expressões genéricas que podem incluir em suas classes o referente fusca, visto que é possível dizer que o fusca é um carro, é um veículo e é, também, um dos modelos da Volkswagen.

Ainda nesse mesmo trecho, é possível perceber que, em alguns casos, essas palavras genéricas (hiperônimos) são utilizadas para substituir expressões maiores, como ocorre em estava sendo vendido com ágio de até $R S \widehat{11}$ mil sobre o preço de tabela que é retomada/substituída por prática, que, nessa situação, designa a ação de vender carros com preço acima dos valores de tabela. Percebemos, dessa forma, que a substituição por hiperônimos contribuiu para o estabelecimento da continuidade temática e da coesão do texto, visto que é um dos recursos que viabilizam a construção dos nexos de equivalência.

\section{O LÉXICO EM SALA DE AULA}

Mediante o exposto, apresentaremos, neste tópico, um recorte dos resultados de uma pesquisa-ação realizada em 2013, na qual trabalhamos essas relações semânticolexicais na perspectiva da textualidade com alunos de 10 ano do ensino médio.

Na ocasião, elaboramos e executamos com esses alunos 
uma Sequência Didática (SD) de estudo do artigo de opinião, incluindo atividades de estudo do léxico, tendo em vista alguns dos problemas evidenciados em textos dos participantes da pesquisa. Como um dos problemas mais recorrentes das produções desses alunos foi o estabelecimento da coesão textual, o principal objetivo desse conjunto de atividades foi levar os alunos a conhecerem alguns dos recursos e procedimentos por meio dos quais o mecanismo de textualização em questão é estabelecido e, assim, sanar algumas das necessidades evidenciadas em suas produções.

Por questões metodológicas, realizamos um recorte do corpus de nosso trabalho e apresentaremos aqui apenas uma das questões de um exercício de estudo da sinonímia e outra de estudo da hiperonímia.

\subsection{A SINONÍMIA, A COESÃO LEXICAL E O SENTIDO DO TEXTO}

Um dos problemas evidenciados nas primeiras produções dos alunos foi a repetição excessiva de alguns termos. Por isso uma das atividades elaboradas - com o intuito de levá-los a perceber o quanto esse problema pode tornar um texto cansativo e inexpressivo - consistiu em apresentar textos com excessiva repetição de termos e solicitar que eles realizassem substituições lexicais, buscando tornar o enunciado mais coeso e expressivo. 
QUADRO 01: Questão do exercício sobre sinonímia e substituição lexical

1. Conforme já discutimos durante as aulas, em alguns casos, a repetição de termos pode ser considerada um problema da produção que afeta o estabelecimento da coesão. Leia os textos abaixo e procure substituir as expressões repetidas em excesso por sinônimos ou outras expressões que você considere adequadas. Lembre-se que, em alguns casos, também podemos omitir os termos para criar os nexos coesivos.

a. O papa João Paulo II disse ontem, dia de seu 770 aniversário, que seu desejo é "ser melhor". O papa João Paulo II reuniu-se na igreja romana de Ant'Attanasio com um grupo de crianças, uma das quais disse: "No dia do meu aniversário minha mãe sempre pergunta o que eu quero. E você, o que quer? O papa João Paulo II respondeu: "Ser melhor". Outro menino perguntou ao papa João Paulo II que presente gostaria de ganhar neste dia especial. "A presença das crianças me basta", respondeu o papa João Paulo II. Em seus aniversários, o papa João Paulo II costuma compartilhar um grande bolo, preparado por irmã Germana, sua cozinheira polonesa, com seus maiores amigos, mas não sopra as velinhas, pois este gesto não faz parte das tradições de seu país, a Polônia. Os convidados mais frequentes a compartilhar nesse dia a mesa com o papa João Paulo II no Vaticano são o cardeal polonês André Marie Deskur e o engenheiro Jerzy Kluger, um amigo judeu polonês de colégio. Com a chegada da primavera, o papa João Paulo II parece mais disposto. O papa João Paulo II deve visitar o Brasil na primeira quinzena de outubro.

Fonte: Exercícios elaborados pelas autoras da pesquisa 
Como é possível perceber, no texto utilizado no exercício, a repetição lexical configura-se como um problema, pois a recorrência excessiva da expressão 'papa João Paulo II' torna-o redundante. Nesse sentido, pretendemos verificar a percepção dos alunos quanto ao problema causado pela repetição desses termos e levá-los a explorar os conhecimentos adquiridos a respeito da sinonímia e da substituição lexical ao tentar resolver tal problema.

Cientes de que outras expressões como hiperônimos ou caracterizadores situacionais poderiam ser utilizadas para realizar essas substituições, deixamos explícito, no enunciadobase, que eles deveriam substituir os termos repetidos por sinônimos ou 'outras expressões que considerassem adequadas', de modo que tal atividade serviria não só para reforçar o estudo da sinonímia, mas também para realizar uma possível introdução para a abordagem dos outros recursos viabilizadores da substituição lexical.

Ao analisarmos os resultados, organizamos as seguintes categorias: na primeira, encontram-se aqueles textos nos quais os alunos realizam substituições apenas por sinônimos; na segunda, os que apresentam, além da sinonímia, retomadas por hiperônimos e caracterizadores situacionais; na terceira, aqueles que, mesmo tendo realizado algum tipo 
de substituição, não conseguem resolver o problema, pois incorrem em novas repetições.

Resposta 1 - (D.R.S.B)

\section{Respostas}

a) O papa João Paulo II disse ontem, dia do seu 77ㅇa aniversário, que seu desejo é "ser melhor". O santo padre reuniu-se na igreja romana de Ant'Attanasio com um grupo de crianças, uma das quais disse: no dia do meu aniversário minha mãe sempre pergunta o que eu quero. E você, o que quer? O sumo pontífice respondeu: "ser melhor". Outro menino perguntou ao papa que presente ele gostaria de ganhar neste dia especial. "A presença das crianças me basta", respondeu João Paulo II. Em seus aniversários, o pontífice costuma compartilhar um grande bolo, preparado por irmã Germana, sua cozinheira polonesa, com seus maiores amigos, mas não sopra as velinhas, pois este gesto não faz parte das tradições de seu país, a Polônia. Os convidados mais frequentes a compartilhar nesse dia a mesa com o papa João Paulo II no Vaticano são o cardeal polonês André Marie Deskur e o engenheiro Jerzy Kluger, um amigo judeu polonês de colégio. Com a chegada da primavera, o santo padre parece mais disposto e deve visitar o Brasil na primeira quinzena de outubro.

No fragmento acima, a expressão definida papa João Paulo I/ é substituída por termos que podem ser considerados sinônimos de papa, tendo em vista sua equivalência semântica e textual. Tais substituições, além de não terem 
afetado negativamente o sentido do texto, atribuíram-Ihe um nível maior de formalidade, visto que há uma diferença considerável entre referir-se ao ex-bispo de Roma apenas como 'papa João Paulo II' e como 'sumo pontífice' ou 'santo padre', pois essas duas expressões apresentam uma carga semântica que indica superioridade do indivíduo assim nomeado e respeito da parte de quem assim o chama. 0 aluno ainda substitui a expressão repetida pelos termos pontífice e João Paulo II. Por fim, na última linha do texto, para sanar o problema da repetição, ela se utiliza da coesão por elipse e opta por eliminar a expressão repetida.

Embora essa atividade possa parecer bastante simples, ressaltamos que, para sua realização, é necessário que o indivíduo esteja a todo momento verificando se as ideias apresentadas articulam-se como um todo significativo. Como afirma Antunes (2005, p. 97), "substituir uma palavra por outra supõe um ato de interpretação, de análise com o objetivo de se avaliar a adequação do termo substituidor quanto ao que pretende conseguir".

Nesse sentido, é possível afirmarmos que, ao substituir papa por santo padre, sumo pontifice e pontífice, houve o entendimento, por parte do aluno, de que essas expressões apresentam sentidos equivalentes que permitiriam assinalar 
a continuidade necessária ao tema do texto, evidenciando, mais uma vez, que a coesão preenche perfeitamente a função de inter-relacionar os segmentos constituintes de nossas produções verbais.

Dos 45 alunos que realizaram essa atividade, 18 (o equivalente a $40 \%$ ) apresentaram respostas semelhantes ao texto analisado, ao reescreverem o texto. Além desses termos, ainda foi possível encontrar, para o texto 1, substituições por sacerdote e prelado, que podem ser consideradas também sinônimos de papa.

Dentre os resultados desse exercício, ainda foi possível encontrar as respostas nas quais as substituições realizadas não foram suficientes para estabelecer a coesão, pois não solucionaram o problema da repetição desnecessária. Tais textos encontram-se na terceira categoria de análise e correspondem a $25 \%$ das respostas, ou seja, totalizam 10 respostas. 
Resposta 2 - (B.S.S - aluno 10 ano)

\section{Exercício}

1. a) O papa João Paulo II disse ontem, dia do seu 77으 aniversário, que seu desejo é "ser melhor". O santo padre reuniu-se na igreja romana de Ant'Attanasio com um grupo de crianças, uma das quais disse: no dia do meu aniversário minha mãe sempre pergunta o que eu quero. E você, o que quer? O santo padre respondeu: "ser melhor". Outro menino perguntou ao santo padre que presente ele gostaria de ganhar neste dia especial. "A presença das crianças me basta", respondeu o santo padre. Em seus aniversários, o santo padre costuma compartilhar um grande bolo, preparado por irmã Germana, sua cozinheira polonesa, com seus maiores amigos, mas não sopra as velinhas, pois este gesto não faz parte das tradições de seu país, a Polônia. Os convidados mais frequentes a compartilhar nesse dia a mesa com o santo padre no Vaticano são o cardeal polonês André Marie Deskur e o engenheiro Jerzy Kluger, um amigo judeu polonês de colégio. Com a chegada da primavera, o santo padre parece mais disposto. $O$ santo padre deve visitar o Brasil na primeira quinzena de outubro.

Como é possível perceber, a resposta acima não apresenta muita diferença quanto ao problema apresentado no texto base, pois a ação do aluno consistiu em substituir papa João Paulo /l por santo padre, o que ocasionou novas repetições desnecessárias. 
A esse respeito, percebemos que, para alguns alunos, o conceito de coesão textual, como recurso por meio do qual estabelecemos os elos entre as partes/segmentos do texto que possibilitam a continuidade necessária à produção, não ficou tão bem esclarecido, necessitando ser retomado e explorado em atividades posteriores.

De um modo geral, é possível afirmarmos que o desempenho dos alunos, ao responderem o bloco de exercícios referentes ao trabalho com a sinonímia, demonstra que relações de sentido como essa podem ser abordadas de maneiras distintas utilizando o texto como elemento base para promoção da reflexão.

\subsection{AS RELAÇÕES DE HIPONÍMIA/HIPERONÍMIA E O PROCEDIMENTO DA SUBSTITUIÇÃO LEXICAL}

Para introduzirmos o estudo desse fenômeno semântico, analisamos, em sala, alguns dos textos reescritos pelos participantes da pesquisa, ao longo das aulas, e solicitamos que explicassem quais relações de sentido podem ser estabelecidas entre expressões como baleia e animal, concessionária e loja, e ainda entre baleia e maior mamífero do oceano, papa e líder da igreja católica.

Tal atividade foi interessante, pois os alunos revelaram reconhecer que existem relações ente os sentidos dessas 
palavras e que são relações de naturezas distintas, afirmando que maior mamífero do oceano é uma característica atribuída à baleia, fato que não ocorre entre concessionária e loja. Mediante essas respostas, explicamos as definições de hiponímia/hiperonímia e caracterizadores situacionais.

Considerando a necessidade de delimitação do corpus, apresentaremos apenas uma questão de um dos exercícios utilizados para o estudo das relações de hiponímia/ hiperonímia. Vejamos:

QUADRO 02: Questão do exercício sobre hiponímia/ hiperonímia

1. Leia o texto abaixo e responda:

Apple anuncia novo iPhone com tela maior e conexão à rede 4G1

iPhone 5 é sucessor do iPhone 4S, lançado em outubro de 2011. Companhia também anunciou nova linha de iPods.

A Apple anunciou, nesta quarta-feira (12), seu novo smartphone, o iPhone 5. O aparelho é a sexta geração do iPhone, cujo primeiro modelo foi lançado em 2007, e vem com uma tela maior do que a versão anterior e compatibilidade com a rede 4G.[...] A câmera principal do celular (a traseira) segue com 8 MP, como na versão anterior do iPhone, mas agora traz um recurso que permite fazer fotos panorâmicas sem a necessidade de um aplicativo extra --as panorâmicas chegam a ter a resolução de $28 \mathrm{MP}$, diz a companhia. 
a. Cientes de que a forma como as palavras são dispostas nos enunciados contribui para a construção de sentido do texto, reescreva o trecho acima alterando/modificando a posição dos hipônimos/hiperônimos utilizados e acrescentando outras expressões que poderiam ser utilizadas para retomar o item em questão. Em seguida comente se houve alguma alteração de sentido do texto ou não.

Fonte: Exercícios elaborados pelas autoras da pesquisa

Esse exercício teve como principal objetivo verificar e reforçar o conhecimento dos alunos a respeito das relações entre hiperônimos e hipônimos e evidenciar a utilização dessas palavras para o estabelecimento dos nexos de reiteração. Para tanto, os alunos deveriam reescrever a notícia reorganizando/alterando a disposição dos termos hiponímicos e hiperonímicos nele presentes. Os discentes poderiam, ainda, acrescentar termos/expressões que, por ventura, pudessem ser utilizadas para estabelecer a coesão textual e que não estivessem presentes no texto. Ao final dessa atividade, os alunos deveriam comparar os dois textos - o texto base e 0 reescrito - a fim de verificar se as modificações realizadas teriam ou não alterado o sentido do texto.

Chegamos a dois resultados diferentes: no que se refere à manutenção da coesão, um considerável número de 
indivíduos - 36 alunos, $80 \%$ dos participantes da atividade - conseguiu realizar as substituições e manter os nexos que possibilitam a coesão do texto. Os 20\% restantes, ou seja, 9 alunos, acabaram se perdendo na realização da atividade e realizaram substituições inadequadas que afetaram a coesão.

Quanto ao outro quesito observado, 27 alunos (60\%) omitiram qualquer comentário comparativo entre as questões; $22 \%$, o equivalente a 10 alunos, conseguiram se posicionar como leitores críticos de seus textos, apontando, inclusive, os aspectos negativos de seus textos. E apenas 8, ou seja, $18 \%$ dos alunos, revelaram ainda não conseguirem admitir/ enxergar suas falhas, visto que realizaram comentários que não condizem com a realidade de seus textos.

Tais constatações podem ser comprovadas através da análise dos fragmentos a seguir. 
Resposta 1 - (L.A.N.S - 2o ano)

A Apple anunciou, nesta quarta-feira (12), seu novo aparelho, o iPhone 5. O celular é a sexta geração do iPhone, cujo modelo foi lançado em 2007. Vem com uma tela maior que a versão anterior e compatibilidade com a rede 4G. A câmera principal do iPhone (a traseira) segue com $8 \mathrm{mp}$, como a versão anterior do Smartphone, mas agora com um recurso que permite fazer fotos panorâmicas sem a necessidade de um aplicativo extra, as panorâmicas chegas a ter a resolução de $28 \mathrm{MP}$, diz a companhia.

Comentário: acredito que a forma como as palavras estão organizadas não alteram o sentido do texto, apesar de deixa-lo menos chamativo.

É perceptível que o aluno consegue realizar as 'trocas' (um terço) entre hipônimos e hiperônimos, mantendo a conexão entre as partes constituintes da notícia e a progressão/continuidade na apresentação das informações fundamentais ao gênero, atendendo, portanto, aos objetivos da questão. Tendo em vista a disposição dos termos nos textos reescritos, é evidente que a notícia apresenta as informações numa ordem mais direta, mais objetiva, o que o torna menos chamativo, como o próprio aluno ressalta em seu comentário, revelando ao mesmo tempo o entendimento a respeito da coesão textual e seu posicionamento crítico a respeito de suas produções, fato que não ocorre com o autor da resposta a seguir. 
Resposta 2 - (E.C.N - 10 ano)

Nesta quarta-feira é anunciado, novo aparelho, celular é a sexta geração do smartphone cujo primeiro modelo foi lançado em 2007, vem como tela maior do que a outra versão anterior e compatibilidade com a rede 4G [...] A câmera principal do iPhone (a traseira) segue com 8MP, na versão anterior do IPhone, mas agora fazer um recurso que permite trazer fotos panorâmicas sem a necessidade de um aplicativo extra - as panorâmicas chegam a ter a resolução de $28 \mathrm{mp}$ diz a companhia.

Comentário: Alteração feita em seguida achei que não ouve modificação pois o sentido é o mesmo.

Nesse texto, o aluno não só não reorganizou a disposição dos hipônimos e hiperônimos como também não conseguiu manter a informatividade e a coesão necessárias ao texto. Observando a resposta, percebemos que duas informações essenciais ao gênero foram eliminadas, de modo que não há como saber qual celular foi lançado, nem quem é o fabricante do produto. No que se refere ao posicionamento desse indivíduo, enquanto leitor crítico de seu próprio texto, percebemos que não houve esse processo de reflexão e autocrítica, pois o aluno não reconhece que as alterações realizadas, além de afetarem a coesão do texto, afetaram a constituição e unidade significativa do gênero. A falta de percepção é tamanha que ele chega afirmar que as alterações não modificaram o texto, pois o sentido foi mantido. 


\section{CONSIDERAÇÕES FINAIS}

De um modo geral, podemos dizer que os exercícios ora apresentados e analisados revelam como diferencial o fato de abordarem as relações semântico-lexicais associadas ao trabalho com o texto, pois contemplam o léxico como elemento essencial para a arquitetura/organização de um texto. Além disso, tais atividades estão diretamente relacionadas às necessidades de aprendizado dos alunos. Conforme dito em momento anterior, cada uma das atividades desenvolvidas ao longo de uma SD deve viabilizar o aprendizado de um gênero, mas também valorizar e aperfeiçoar as capacidades e habilidades já dominadas pelos indivíduos e sanar as dificuldades evidenciadas.

A partir dessa experiência, foi possível percebermos que o ensino de léxico como elemento articulador das conexões semânticas do texto apresenta-se como uma alternativa produtiva ao ensino de língua, pois possibilita não só o aprendizado acerca das relações semântico-lexicais, mas também favorece o desenvolvimento das práticas de leitura, reflexão e escrita, essenciais ao ensino de Língua Portuguesa. 


\section{REFERÊNCIAS}

ANTUNES, I. (2010) Análise de textos: fundamentos e práticas. São Paulo: Parábola Editorial. (Estratégias de ensino; 21) . Lutar com palavras: coesão e coerência. São Paulo: Parábola Editorial, 2005. (Na ponta da língua; v.13)

(1996) Aspectos da coesão do texto - análise em editoriais jornalísticos. Recife: Editora da UFPE.

ILARI B; GERALDI, J.W. (2006) Semântica. 11ed. São Paulo: Ática. (Princípios; 8)

$\mathrm{KOCH}$, I. G. V. (2008) O Texto e a construção de sentidos. 9ed., 1a reimpressão. _ São Paulo: Contexto.

LYONS, J. (1979) Semântica. Princípios gerais. In: . Introdução à Linguística Teórica. São Paulo: Companhia Editorial Nacional. p. 425-469. PALADINO, V. C. [et al]. (2006) Coesão e coerência textuais: teoria e prática. Rio de Janeiro: Freitas Bastos.

Alessandra Magda de Miranda. Possui graduação em Letras - Língua Portuguesa pela Universidade Estadual da Paraíba (2011) e mestrado em Linguística pelo Programa de Pós-graduação em Linguística (PROLING), da Universidade Federal da Paraíba (2014). Atualmente, é professora efetiva da Secretaria Estadual de Educação da Paraíba (SEE/PB) lecionando língua, literatura e redação em turmas de Ensino Fundamental e Médio na E.E.E.F.M. CAIC José Joffily e na E.E.E.F.M. Professor Raul Córdula. Tem experiência na área de Letras, com ênfase em Linguística, atuando principalmente nos seguintes temas: ensino de língua portuguesa, produção textual, coesão, semântica e léxico. Contato: alessandra ufpb@hotmail.com

Mônica Mano Trindade Ferraz. Possui graduação em Letras pela Universidade Estadual de Campinas (1990), especialização em Análise do Discurso pela PUCCAMP (1998), mestrado em Linguística Aplicada pela Universidade Federal de Santa Catarina (2001) e doutorado em Linguística Teórica pela Universidade Federal de Santa Catarina (2006). Atualmente é professora da Universidade Federal da Paraíba. Tem 
experiência na área de Língua Portuguesa e Linguística, com ênfase em Semântica, Linguística Textual e Metodologia de Ensino. Pesquisa e orienta nos seguintes temas: Significação na perspectiva léxicoconceptual, Análise de textos na interface semântico-pragmática, Contribuições da Semântica para o Ensino de Língua Portuguesa. Contato: monicatrin@hotmail.com

(Footnotes)

1 Disponível em: http://g1.globo.com/tecnologia/noticia/2012/09/ apple-faz-evento-em-san-francisco-e-deve-anunciar-novo-iphone.html

Recebido em 11 de novembro de 2014. Aprovado em 15 de novembro de 2014. 